\title{
Modelling the effect of temperature on hatching and settlement patterns of meroplanktonic organisms: the case of the octopus
}

\author{
STELIOS KATSANEVAKIS and GEORGE VERRIOPOULOS \\ University of Athens, Faculty of Biology, Department of Zoology-Marine Biology, 15784 Panepistimioupolis, Athens, \\ Greece. E-mail: skatsan@biol.uoa.gr
}

\begin{abstract}
SUMMARY: The duration of embryonic development and the planktonic stage of meroplanktonic species is highly temperature dependent and thus the seasonal temperature oscillations of temperate regions greatly affect the patterns of hatching and benthic settlement. Based on data from the literature on embryonic development and planktonic duration of Octopus vulgaris (common octopus) in relation to temperature, and on observed temperature patterns, several models of hatching and settlement patterns were created. There was a good fit between observed settlement patterns and model predictions. Based on these models we concluded that in temperate regions: (1) when temperature is increasing (from early spring to mid summer) the hatching and settlement periods tend to shorten, while when the temperature is decreasing (during autumn) the hatching and settlement periods tend to lengthen; (2) hatching and settlement peaks are narrower and more intense than a spring spawning peak but wider and less intense than an autumn spawning peak; (3) at lower latitudes, hatching and settlement patterns tend to follow the spawning pattern more closely, (4) the periodic temperature pattern of temperate areas has the potential to cause a convergence of hatching during spring.
\end{abstract}

Keywords: cephalopod, hatching pattern, Octopus vulgaris, recruitment, settlement, spawning, temperature.

RESUMEN: MODELO DEL EFECTO DE LA TEMPERATURA SOBRE LOS PATRONES DE ECLOSIÓN Y ASENTAMIENTO DE ORGANISMOS MEROPLANCTÓNICOS: EL EJEMPLO DEL PULPO. - La duración del desarrollo embrionario y de la etapa planctónica de especies mereoplantónicas depende mucho de la temperatura, por lo que las variaciones estacionales de este parámetro afectan considerablemente a los patrones de eclosión y al asentamiento bentónico. Basándose en datos bibliográficos sobre la duración del desarrollo embrionario y del periodo planctónico del pulpo común, Octopus vulgaris, en relación con la temperatura y en las pautas de temperatura observadas, se han desarrollado varios modelos predictivos de los patrones de eclosión y asentamiento de los alevines. Se observó la existencia de un buen ajuste entre los modelos y los datos de campo referentes al desove y al asentamiento. Según estos modelos, y para las regiones templadas, se concluye que: $1^{\circ}$ ) cuando aumenta la temperatura (desde principios de la primavera hasta mediados del verano) los periodos de eclosión y asentamiento tienden a reducir su duración, mientras que cuando la temperatura desciende (en otoño) los periodos de eclosión y asentamiento tienden a alargarse; $2^{\circ}$ ) los picos de eclosión y asentamiento son más estrechos e intensos que el pico de desove en la primavera, pero más anchos y menos intensos en el otoño; $3^{\circ}$ ) en latitudes inferiores, los patrones de eclosión y asentamiento tienden a ajustarse mejor a las pautas de desove; y $4^{\circ}$ ) el patrón periódico de la temperatura en áreas templadas tiene capacidad para provocar una convergencia de la eclosión en la primavera.

Palabras clave: cefalópodo, patrón de eclosión, Octopus vulgaris, reclutamiento, asentamiento, desove, temperatura.

\section{INTRODUCTION}

Octopus vulgaris Cuvier 1797 is a coastal, sedentary species, living between 0 and $200 \mathrm{~m}$ depth. Its abundance decreases with depth and is nearly zero at the slope of the continental shelf (Guerra, 1981; Belcari et al., 2002). Its life-span seems to vary between 12 and 18 months (Iglesias et al., 2004; Katsanevakis and Verriopoulos, 2006). O. vulgaris is a simultaneous terminal 
spawner (Rocha et al., 2001) and the females lay roughly 100000 to 500000 eggs (Mangold, 1983). The newly-hatched octopuses spend their first weeks in the plankton, before they settle and lead a benthic life. Both the duration of embryonic development and of planktonic life depend greatly on temperature (Vevers, 1961; Wodinsky, 1972; Mangold and Boletzky, 1973; Villanueva, 1995; Caverivière et al., 1999).

Most temperate sea invertebrates spawn over a long period of time or even during most of the year (Giese, 1959). As periodic temperature fluctuations in temperate regions are significant and the temperature range between summer and winter may exceed $15^{\circ} \mathrm{C}$, the various batches of eggs spawned face different temperature regimes during embryonic development and early life. In meroplanktonic organisms, embryonic development and planktonic duration are strongly temperature dependent and the various temperature regimes faced due to asynchronous spawning result in various hatching and benthic settlement patterns. As hatching and benthic settlement of meroplanktonic organisms are the two key events that largely define the recruitment success of new cohorts, temperature patterns have an important effect on the recruitment of temperate meroplanktonic species. This study deals with the effect of temperature patterns on the hatching and benthic settlement patterns of $O$. vulgaris.

Using data from the literature on the temperature-related duration of embryonic development and the planktonic stage and assuming various spawning patterns, we developed models that predict the seasonal patterns of hatching and benthic settlement of $O$. vulgaris. The models were based solely on temperature effects. The degree of coincidence with the field results revealed the significance of temperature for the hatching and settlement patterns of $O$. vulgaris. There is a lack of data regarding the early life stages of octopuses in comparison to other invertebrate larvae or fishes (Boletzky, 2003). Estimating egg and paralarva abundance is quite difficult and has rarely been done for octopuses; there are only two studies reporting paralarval abundance of $O$. vulgaris (Sakaguchi et al., 1999; González et al., 2005). This is the first attempt to model the $O$. vulgaris early life phases in relation to the physical environment (temperature patterns) and compare this with observed settlement data. To our knowledge, such an approach has not been used before for any other meroplanktonic species.
Although based on O. vulgaris, the methodology and the main conclusions are valid for many other aquatic oviparous meroplanktonic organisms with planktonic hatchlings whose embryonic and/or planktonic stage lasts a few months. There are, however, cases when other factors are also of major importance and should be taken into account. For example, many populations tend to produce smaller eggs with fewer nutrients when the temperature is higher or larger eggs with more nutrients when food availability decreases, as the species' reproductive strategy could be aimed at minimizing the duration of the larval stage (Hutchinson, 1951; Jamieson and Burns, 1988).

\section{MATERIALS AND METHODS}

A time series of water temperature data was gathered during a 27-month study of the ecology of $O$. vulgaris (Katsanevakis and Verriopoulos, 2004a,b, 2006) in Greece (at latitudes between $35.5^{\circ} \mathrm{N}$ and $38^{\circ} \mathrm{N}$ ). During regularly conducted dives, seawater temperature was recorded using an electronic temperature recorder, with an accuracy of $0.1^{\circ} \mathrm{C}$. The temperature was recorded at depths between 5 and 25 m, from July 2001 until September 2003. Using these data, two temperature patterns were examined; the first using available surface temperature data (at a depth of $5 \mathrm{~m}$ ) and the second using available temperature data at a depth of $25 \mathrm{~m}$. A third temperature pattern was also examined, using satellite surface temperatures (SST) from NOAA (http://www.class. noaa.gov) for the same time period, for the area offshore Dakhla (South Morocco; at $\sim 24^{\circ} \mathrm{N}-16^{\circ} \mathrm{W}$ ), where a substantial octopus fishery exists. Non-linear periodic regressions of the form $T(d)=T_{m}+T_{k}$ $\sin (a \cdot d+b)$ were fitted to the 2-year data for each of the three cases, where $T(d)$ is the temperature in relation to day $d$ of the year $(1 \leq d \leq 365), T_{m}$ is the annual mean temperature, $T_{k}$ is the amplitude of the oscillation, $a=2 \pi / 365 \cong 0.0172$, and $b / a$ is the phase shift.

Data on the duration of embryonic development in relation to temperature were gathered from the literature (Vevers, 1961; Wodinsky, 1972; Mangold and Boletzky, 1973; Mangold, 1983; Caverivière et al., 1999). The two-parameter degree-day model $I(T)=\mathrm{K} /\left(T-T_{0}\right)$ was fitted to the data to relate the length of embryonic development of $O$. vulgaris to temperature. 
This $I(T)$ formula gives the duration of development of $O$. vulgaris eggs when the temperature is considered constant and equal to $T$. However, seawater temperature is not constant. The instantaneous developmental rate is $1 / I(T)$ and when this rate is considered to be constant over a short time period $\Delta t$, then the quotient $\Delta t / I(T)$ is equivalent to the proportion of total development occurring in time $\Delta t$ under constant temperature $T$. The predicted time of completed embryonic development corresponds to the day when the sum of these ratios is 1 . Thus, to calculate the duration of embryonic development when the temperature is changing, we assume that if the eggs are successively incubated for time intervals $\Delta t_{1}, \Delta t_{2}, \Delta t_{3}, \ldots$ at temperatures $T_{1}, T_{2}, T_{3}, \ldots$ then hatching will occur when

$$
\sum_{i} \frac{\Delta t_{i}}{I\left(T_{i}\right)}=1
$$

In nature, temperature is a continuous function of time and the duration of embryonic development $I\left(t_{\mathrm{s}}\right)$ as a function of spawning time $t_{\mathrm{s}}$ could be calculated as the limit of this sum when the time intervals $\Delta t_{i}$ become infinitely small:

$$
\lim _{\Delta t \rightarrow 0} \sum_{i} \frac{\Delta t_{i}}{I\left(T_{i}\right)}=1 \Rightarrow \int_{t_{s}}^{t_{s}+I\left(t_{s}\right)} \frac{d t}{I(T(t))}=1
$$

Similarly, data on the duration of the planktonic stage $P(T)$ in relation to temperature were gathered from the literature (Itami et al., 1963; Imamura, 1990; Villanueva, 1995) and a regression equation was estimated. Following the same reasoning as for the duration of embryonic development, the planktonic duration of $O$. vulgaris as a function of hatching time $t_{h}$ could be estimated by the equation:

$$
\lim _{\Delta t \rightarrow 0} \sum_{i} \frac{\Delta t_{i}}{P\left(T_{i}\right)}=1 \Rightarrow \int_{t_{h}}^{t_{h}+P\left(t_{h}\right)} \frac{d t}{P(T(t))}=1
$$

The following hypothetical annual spawning patterns were considered: (S1) The spawning period lasts exactly one month starting from the first day till the last day of the month and the production of eggs is uniform for all days. During the other months there is zero spawning. This spawning pattern was repeated for each of the 12 months. (S2) Spawning is uniform throughout the year. (S3) Spawning occurs all year round, but a spawning peak is observed during early spring. (S4) Spawning occurs all year round and two spawning peaks are observed, one in early spring and one in autumn.

For each batch of eggs spawned at $t_{s}$, the corresponding hatching time was estimated as $t_{h}=t_{s}+I\left(t_{s}\right)$ and the corresponding settlement time as $t_{h}+P\left(t_{h}\right)$. Thus, for each spawning pattern, the corresponding hatching and settlement patterns were estimated. A simple spreadsheet in Ms Excel was used for all calculations. We assumed $100 \%$ hatching success for the eggs and zero mortality for the planktonic hatchlings. Although these assumptions are far from being true, the results are still of great value, as the potential for the temporal pattern of hatching and benthic settlement was defined in this way.

The temporal pattern of benthic settlement of $O$. vulgaris was estimated by Katsanevakis and Veriopoulos (2006), in the eastern Mediterranean and at depths from 5 to $25 \mathrm{~m}$; in the above paper this pattern is given as variable $N_{l}$ which represents individuals that enter size class 1 during a projection interval of a $1 / 4$ of a month. Variable $N_{1}$ was transformed to represent monthly settlement and compared with the models of the present study, based on surface temperature and with spawning patterns S2, S3 and S4. Each model was scaled to best fit the observed data by minimizing the sum of squares (SS) of the differences between observed densities and model values.

All the regressions of this study were calculated with DataFit v.8.0.32 software (Oakdale Engineering), using the non-linear least squares method with iterations.

\section{RESULTS}

The three temperature regressions used in this study were (Fig. 1):

$$
\begin{aligned}
& T_{5}\left({ }^{\circ} \mathrm{C}\right)=20.65-6.59 \sin (0.0172 d+19.74) \\
& \text { at } 5 \mathrm{~m} \text { depth } \\
& T_{25}\left({ }^{\circ} \mathrm{C}\right)=19.11-5.59 \sin (0.0172 d+19.28) \\
& \text { at } 25 \mathrm{~m} \text { depth } \\
& T_{\text {Mor }}\left({ }^{\circ} C\right)=19.09-1.44 \sin (0.0172 d+18.57) \\
& \text { SST, Morocco (Dakhla) }
\end{aligned}
$$

where $T$ is the temperature and $d$ the day of the year (1-365).

The degree-day model relating the duration of embryonic development to temperature was $I(T)=$ $532.2 /(T-8.763)$, where $I(T)$ is in days and $T$ in ${ }^{\circ} \mathrm{C}$ 


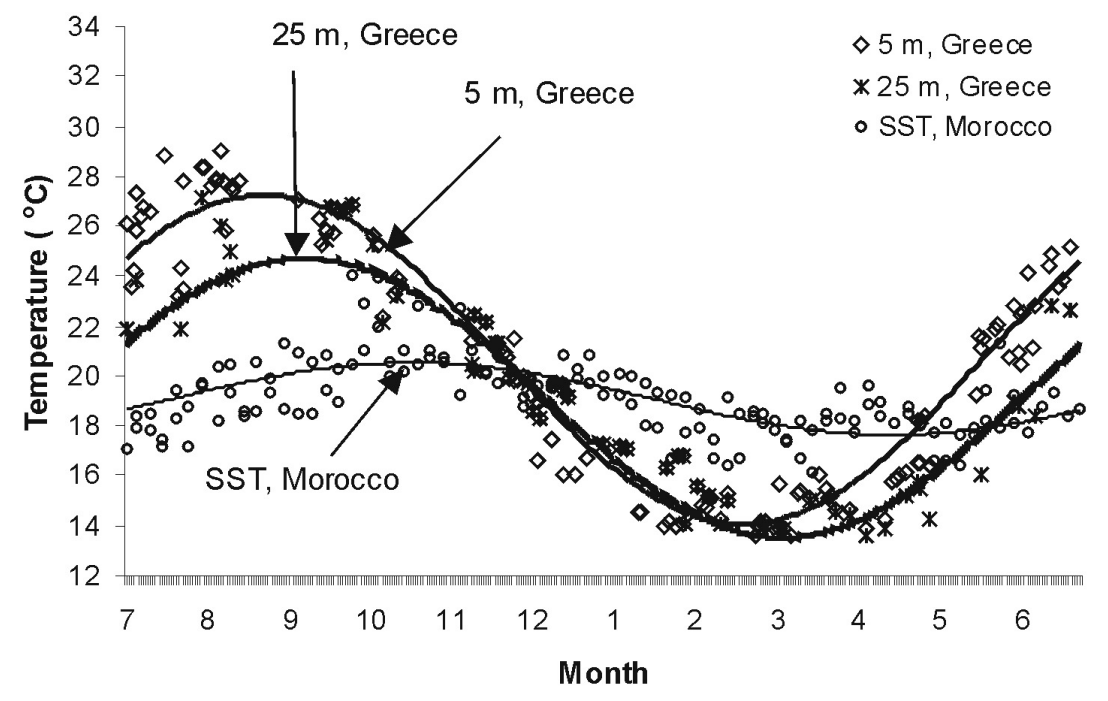

FIG. 1. - The three different temperature patterns used in this study.

(Fig. 2). After substituting the formulas derived for $I(T)$ and $T(t)$ in the integral of Equation 1 and integrating, we found:

$$
k_{0} I+k_{1}\left\{\cos \left[k_{2}\left(t_{s}+I\right)+k_{3}\right]-\cos \left[k_{2} t_{s}+k_{3}\right]\right\}=1
$$

The values of parameters $k_{0}, k_{1}, k_{2}$, and $k_{3}$ for each of the four temperature patterns are given in Table 1 . These equations, which give $I\left(t_{\mathrm{s}}\right)$ in a complex form were arithmetically solved for each case using the Newton-Raphson method (e.g. Ellis and Gulick, 1986: 168) for all values of $t_{s}$ between 0 and 365 with a step of 5 days. The results are given graphically in Figure 3. In all cases, we observed one minimum and one maximum in $I\left(t_{\mathrm{s}}\right)$. In Greece, the shortest duration

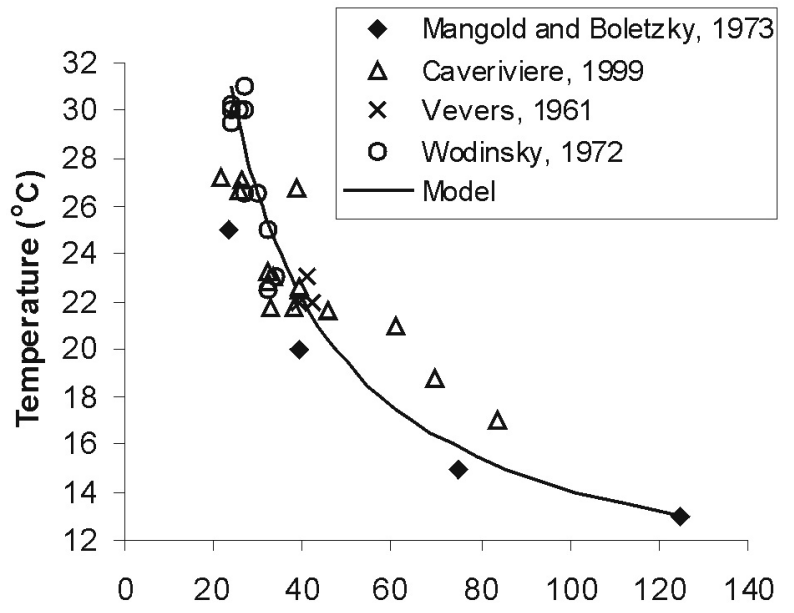

Duration of embryonic development (days)

Fig. 2. - Data on duration of embryonic development of $O$. vulgaris in relation to temperature, gathered from several sources of the literature, together with the degree-day model that fits the data. of embryonic development was for eggs spawned during August at depths of both 5 and $25 \mathrm{~m}$ and the longest was for eggs spawned in mid-winter. In Morocco, the shortest duration of embryonic development was for eggs spawned during SeptemberOctober and the longest for eggs spawned in March. There was a lot less variation in the duration of embryonic development in Morocco than in Greece.

Very little information was found on the duration of the planktonic phase. Therefore, it was not feasible to develop a reliable regression equation that correlated planktonic duration with temperature. Nevertheless, for the purposes of our study and for prediction purposes only, a least squares straight line was fitted to the available data (Fig. 4) with equation $P(T)=157.5-5.008 T\left({ }^{\circ} \mathrm{C}\right)$, where $P(T)$ is in days and

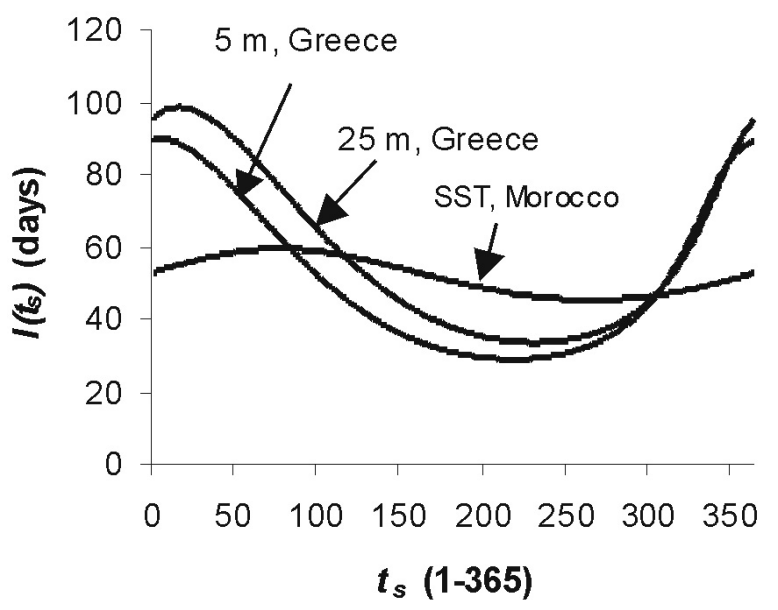

FIG. 3. - Duration of embryonic development in relation to the day of the year the eggs were spawned $\left(t_{\mathrm{s}}\right)$ for the three temperature patterns in Fig. 1. 
TABLE 1. - The values of parameters $k_{0}, k_{1}, k_{2}, k_{3}$ and $m_{0}, m_{1}, m_{2}, m_{3}, m_{4}$ of the complex equations giving $I\left(t_{\mathrm{s}}\right)$ and $P\left(t_{\mathrm{h}}\right)$ respectively, as functions of spawning time $t_{\mathrm{s}}$ and hatching time $t_{\mathrm{h}}$, (Equations 3 and 4 ), for each of the four temperature patterns used.

\begin{tabular}{lccccccccc}
\hline & $k_{0}$ & $k_{1}$ & $k_{2}$ & $k_{3}$ & $m_{0}$ & $m_{1}$ & $m_{2}\left(\times 10^{-3}\right)$ & $m_{3}$ & $m_{4}$ \\
\hline 5 m, Greece & 0.02234 & 0.7193 & 0.01721 & 19.54 & 2.712 & 1.262 & 0.009 & 9.770 & 0.6102 \\
25 m. Greece & 0.01944 & 0.6102 & 0.01721 & 19.28 & 2.109 & 1.122 & 0.009 & 9.640 & 0.4530 \\
SST. Morocco & 0.01940 & 0.1572 & 0.01721 & 18.57 & 1.890 & 1.007 & 0.009 & 9.285 & 0.1165 \\
\hline
\end{tabular}

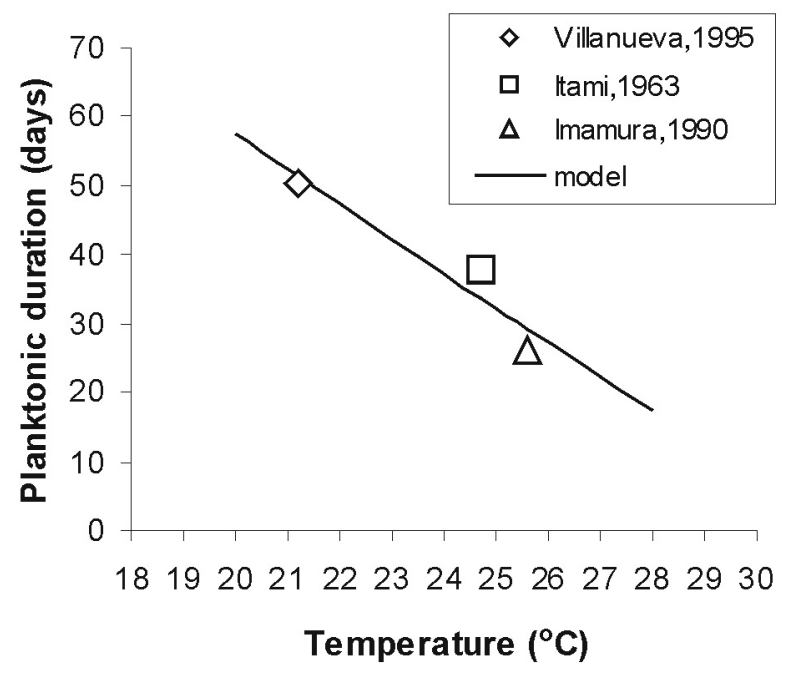

FIG. 4. - Data (from the literature) of planktonic duration of $O$. vulgaris in relation to temperature, together with the best-fit linear model.

$T$ in ${ }^{\circ} \mathrm{C}$. After substituting the formulas derived for $P(T)$ and $T(t)$ in the integral of Equation 2 and integrating, we found:

$$
\left\{m_{0} \cdot \tan ^{-1}\left[m_{1} \cdot\left(\tan \left(m_{2} \cdot t+m_{3}\right)+m_{4}\right)\right]\right\}_{t_{h}}^{t_{h}+P\left(t_{h}\right)}=1
$$

The values of parameters $m_{0}, m_{1}, m_{2}, m_{3}$, and $m_{4}$ for each of the four temperature patterns are given in Table 1 . This equation, which gives $P\left(t_{\mathrm{h}}\right)$ in a complex form was arithmetically solved using the Newton-Raphson method (e.g. Ellis and Gulick, 1986: 168) for all values of $t_{h}$ between 0 and 365 with a step of 5 days. The results are given in Figure 5 . We observed one minimum and one maximum in planktonic duration during the same periods of the year that the minimum and maximum values of the duration of embryonic development occur (Fig. 3).

The hatching and settlement patterns for the 12 monthly cases of $\mathrm{S} 1$, using temperature pattern $T_{5}$, are presented in Figure 6. As expected, the time delay between spawning and settlement is lower during the 'hot' period (less than two months) than during the 'cold' period (up to six months). In additional, when temperature is increasing (from early spring to mid summer) the hatching and settlement

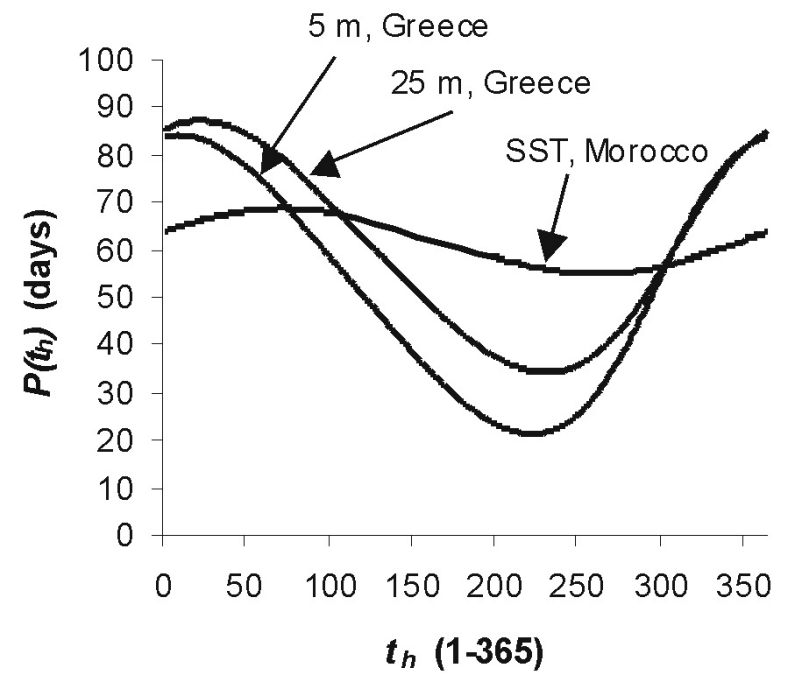

FIG. 5. - Planktonic duration in relation to the hatching day of the eggs $\left(t_{\mathrm{h}}\right)$ for the three temperature patterns in Fig. 1.

periods tend to shorten in relation to the corresponding spawning period, while when temperature is decreasing (during autumn) the hatching and settlement periods tend to lengthen in relation to the spawning period. Characteristically, O. vulgaris' eggs spawned during the five-month interval from January to May will all settle during June and July (Fig. 6). As a consequence, when constant spawning during the year is assumed (S2), there is a tendency for hatching and settlement patterns to peak in the period of increasing temperature and to have a minimum in the period of low temperature. The magnitude and timing of the peak depends on $I(T)$ and $P(T)$. When scenario S3 is assumed, then the hatching and settlement peaks are more intense, since the temperature pattern acts in synergy with the spawning peak (Figs. 7, 8). However, the temperature pattern acts in opposition to a spawning peak in autumn and tends to flatten it (Figs. 7, 8).

Assuming that octopus paralarva remain at greater depths (at $25 \mathrm{~m}$ ), a time delay of the summer main hatching or settlement peaks occurs. The secondary autumn peaks are not affected (Figs. 7,8), as the temperature patterns between $5 \mathrm{~m}$ and $25 \mathrm{~m}$ differ significantly only in the period of increasing 

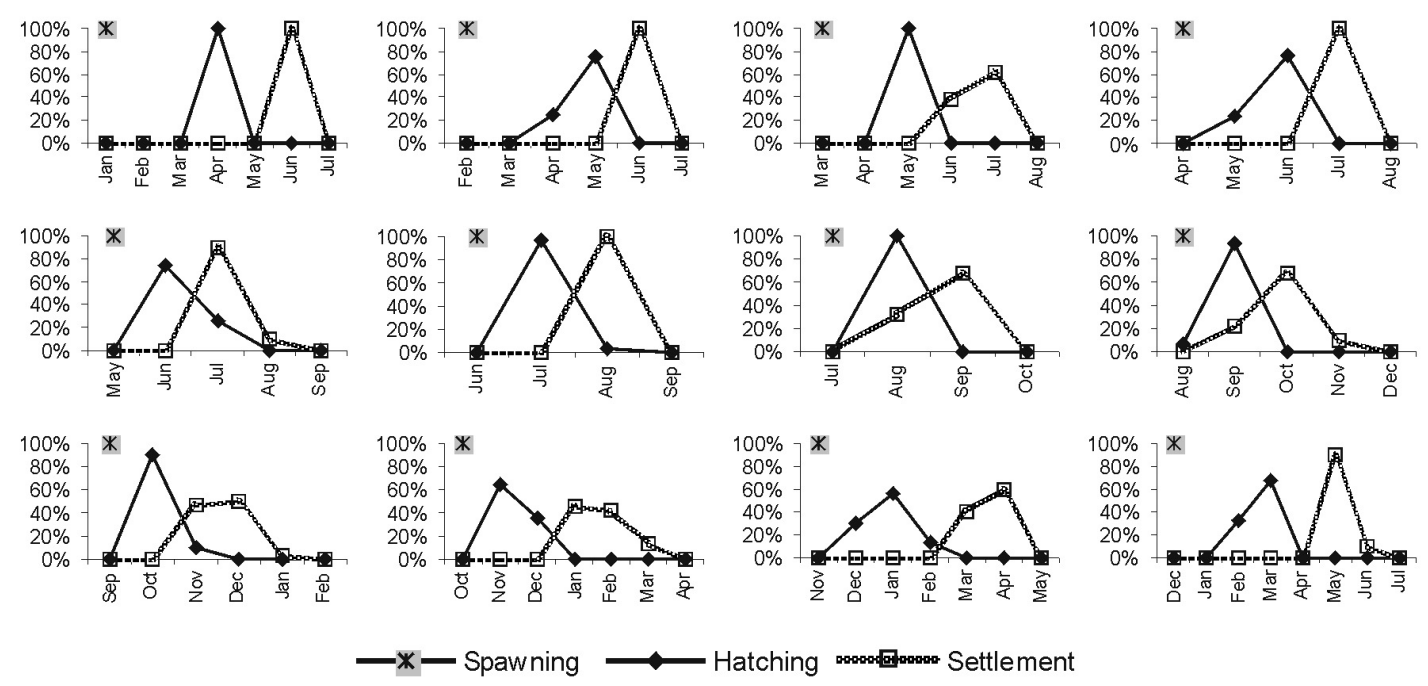

FIG. 6. - The hatching and settlement patterns, according to the 12 hypothetical scenarios (S1) that spawning lasts exactly one month with a constant daily rate and is zero during the rest of the months. The spawning episode and the following hatching and settlement patterns are given for each of the 12 months. The temperature pattern $T_{5}$ was used (at $5 \mathrm{~m}$ depth in Greek waters).



S3 (One spawning peak in spring)

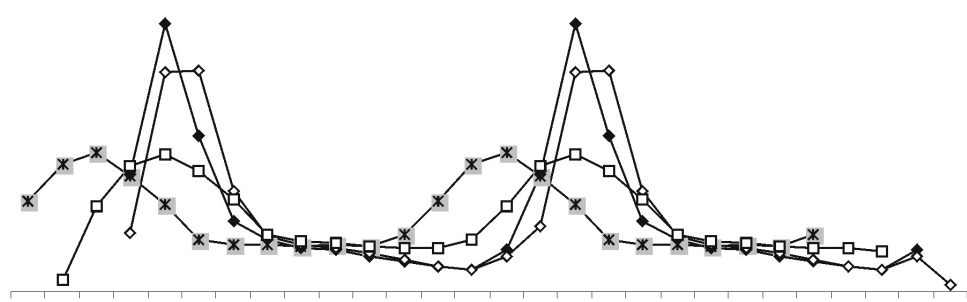

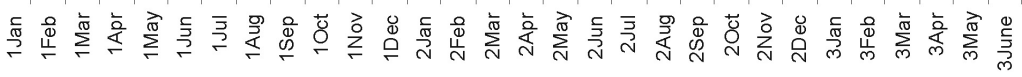



FIG. 7. - The hatching patterns found for 3 different spawning scenarios (S2, S3, S4). 

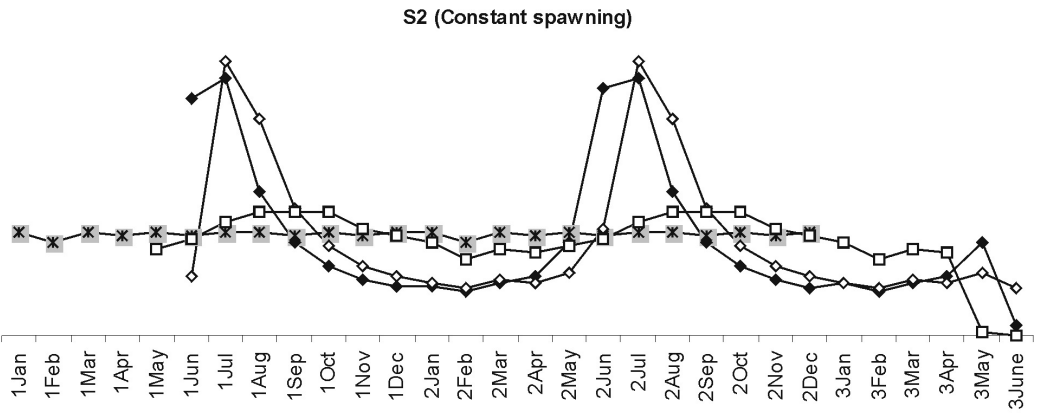

S3 (One spaw ning peak in spring)

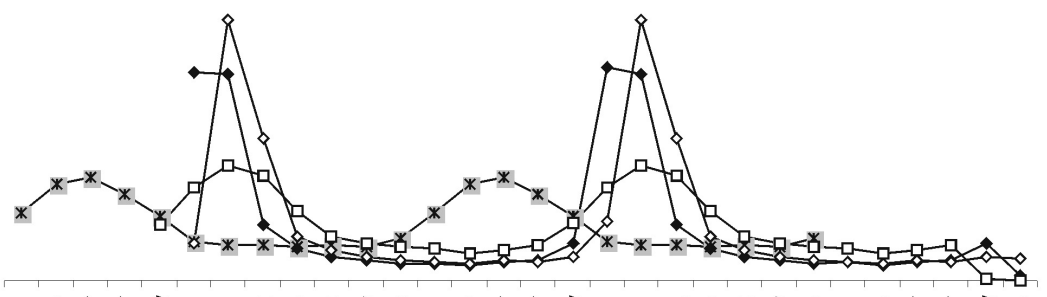



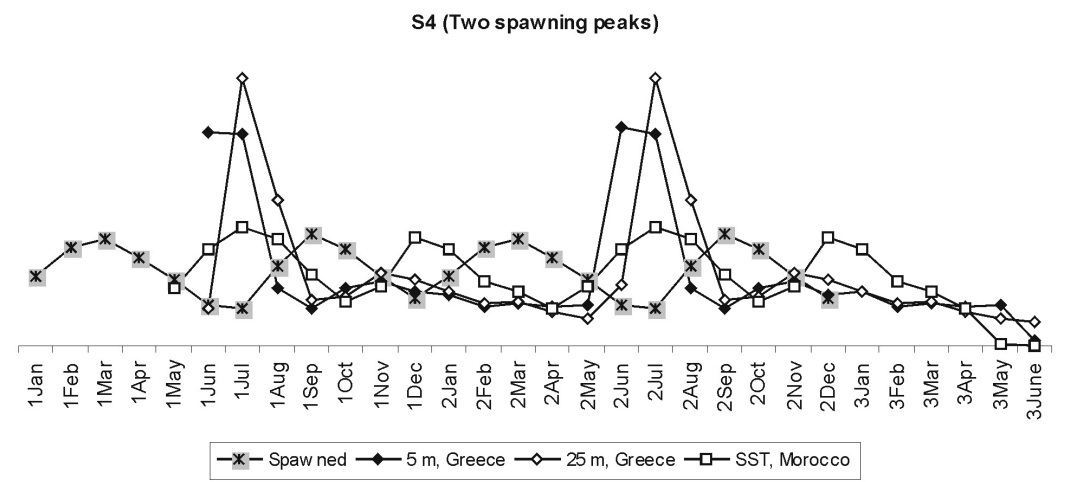

FIG. 8. - The benthic settlement patterns found for 3 different spawning scenarios (S2, S3, S4).

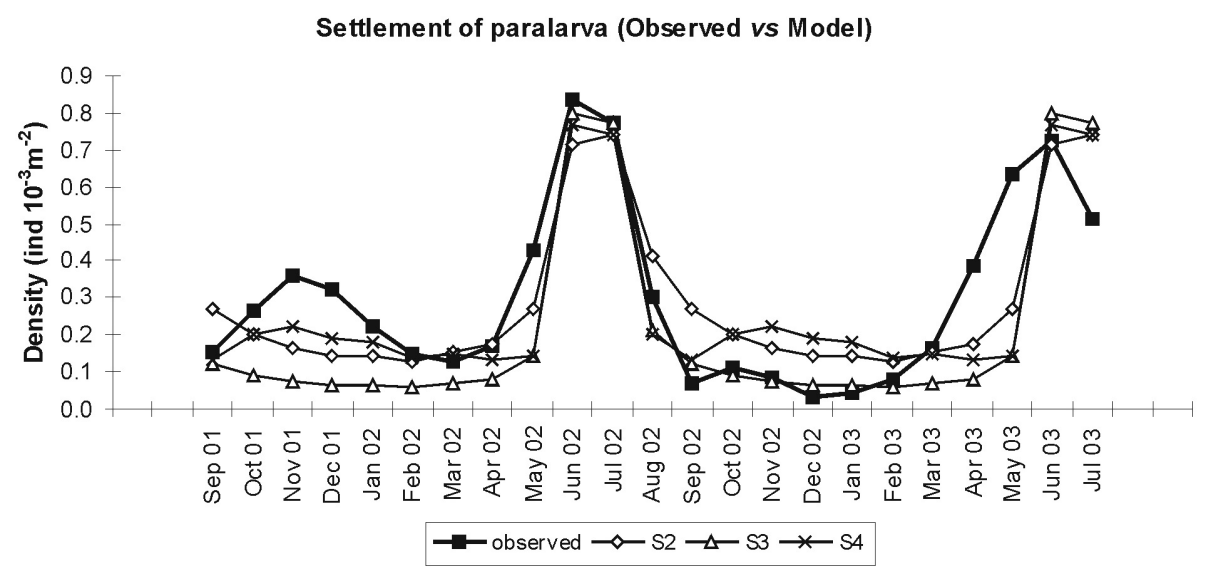

FIG. 9. - The observed benthic settlement pattern in the field of $O$. vulgaris and the settlement models for the three different spawning scenarios (S2, S3, S4), using the $T_{5}$ temperature pattern (Greece, at $5 \mathrm{~m}$ depth).

temperature, when there is an intense thermocline (Fig. 1). Off the south of Morocco, hatching and settlement patterns tend (with a time delay) to follow the spawning pattern much more closely (Figs. 7, 8).
Thus, when spawning is constant throughout the year, the lower the annual temperature variation (i.e. the lower the latitude) the more uniform the hatching and settlement patterns. 
The observed $v s$. modelled patterns of settlement are shown in Figure 9. The 'constant spawning' model fits the observed data better $\left(\operatorname{adj}-\mathrm{R}^{2}=0.64\right.$, $\mathrm{p}<0.0001)$ than the 'one peak' $\left(\operatorname{adj}-\mathrm{R}^{2}=0.41\right.$, $\mathrm{p}=0.0006)$ or the 'two peak' model $\left(\operatorname{adj}-\mathrm{R}^{2}=0.54\right.$, $\mathrm{p}<0.0001$ ). If we restrict the comparison only to the first 12 months with available data, there is a substantially better fit with adj- $\mathrm{R}^{2}=0.76,0.47$ or 0.81 (and corresponding p-values, 0.0001, 0.0080, $<0.0001$ ) for the three spawning patterns S2, S3 and $\mathrm{S} 4$ respectively.

\section{DISCUSSION}

The degree-day model, although widespread, has often been criticized because of its lack of accuracy at extreme temperatures. Many models have been suggested to account for the nonlinearity of the developmental rate at low or high temperatures (Hamel et al., 1997), even though in many cases the degree-day model gives better estimates than these non-linear models (Hochberg et al., 1986). With aquatic poikilotherms, this is especially true for the majority of management purposes because the extreme temperatures at which the degree-day model is known to be inaccurate rarely occur in seawater, in contrast to terrestrial habitats. Indeed, in our case, the temperature range that occurred in the field (Fig. 1) is narrower than the temperature range in the incubation experiments used for our model (Fig. 2). Thus, the degree-day model was chosen in this study due to its simplicity and the biological meaning of its parameters (Hamel et al., 1997).

The lack of sufficient data on the planktonic duration of $O$. vulgaris hatchlings implied that equation $P(T)$ was not very accurate, which caused further unreliability for equations $P\left(t_{\mathrm{h}}\right)$ especially for values that were distant from the range of available data and mostly for values below $20^{\circ} \mathrm{C}$. Nevertheless, the general shape of $P\left(t_{\mathrm{h}}\right)$, as given in Figure 5, would not change much.

Egg mortality was assumed to be zero. After laying the eggs, the female octopus rarely leaves the egg mass till hatching. Egg care includes cleaning the eggs with the arm tips, directing jets of water from the funnel through the strings and pushing away intruders. Due to this care, hatching success in octopuses is very high (Hanlon, 1977; Mangold, 1983) and our assumption of zero mortality is not far from reality.
The highest mortality rate of this species occurs during the planktonic stage of its life cycle (Mangold, 1983); this is valid for the vast majority of benthic species with a planktonic early stage. It is logical to assume that although mortality will greatly reduce the number of hatched paralarva that will eventually survive to settle, the overall temporal pattern of benthic settlement will not change much in shape. It would be paradoxical from an evolutionary point of view and a great waste of energy for a species to have a peak in the hatching pattern at a season of high planktonic mortality and not to utilize a period of low mortality. Thus, the temporal patterns of benthic settlement that were found in this study, assuming zero mortality, are not expected to deviate much in shape from the true picture.

Wodinsky (1972) found that O. vulgaris spawns throughout the year in the western Atlantic. Mangold (1983) found a 9-month spawning period (except winter) in the Mediterranean. Spawning during the whole year with two main periods in spring and autumn has been reported in the eastern Atlantic off the coast of south Morocco (Hatanaka, 1979) and off the island of Gran Canaria (Hernández-García et al., 2002). Spawning from February to October with two peaks in April-May and August was found in SW Spain (Silva et al., 2002). Two spawning peaks were also found in Greece (NE Mediterranean), a main one during late winter-spring and one of minor importance during late summer-autumn (Katsanevakis and Verriopoulos, 2006). On the Saharan Bank and adjacent areas, spawning seems to occur all year round with a peak during spring and a minor peak in some years in late summer or early autumn (Balguerías et al., 2002). Thus, the three different spawning patterns (S2, S3, S4) chosen, represent the various patterns found for $O$. vulgaris' spawning in different geographical areas. However, it has to be noted that there is an infinite number of different spawning scenarios apart from the ones used (with different peak intensities or widths, different relative intensities of peaks etc.) and many of them could produce better fits; but the general patterns and conclusions of our approach remain.

Under the assumptions of this study, the modified 'constant spawning' model best fits the observed data in Greece. The model was created based exclusively on the effects of temperature on embryonic development and planktonic duration, 
assuming that mortality does not change the patterns. The fact that the model fits the observed data adequately shows the significance of temperature for determining the hatching and benthic settlement patterns of the common octopus. Specifically, the summer peak of benthic settlement, which was evident in all the models of this study, was found to be independent of the spawning pattern and is mainly temperature-defined.

Balguerías et al. (2002) reported two periods of recruitment off the south of Morocco, a main one in autumn and a minor one in spring, which are both shifted a few weeks from our model predictions of settlement. This is expected, as 'recruitment', when estimated by a fishery survey, usually refers to juveniles that have grown to a size that renders them catchable by fishing tools and not to just-settled individuals. For $O$. vulgaris, there are a few weeks between settlement and becoming large enough to be caught by standard fishing tools and thus this time lag between observed recruitment and the model predictions for settlement is expected.

Asynchronous growth, and maturation and spawning over many months or throughout the year give a population the potential to exploit available food resources and overcome short adverse environmental episodes more efficiently. However, an extended period of hatching and benthic settlement would cause a significant waste of offspring, as a great percentage of hatchlings would spend their fragile planktonic lives under unfavourable conditions. Taking this into account, the two spawning peaks observed in most studies in temperate regions are probably related to the two planktonic blooms that occur in spring (major) and autumn (minor). The periodic temperature pattern of temperate regions causes a convergence of hatching and settlement when the temperature is increasing. Thus, the majority of offspring benefits from the high availability of food during the major spring planktonic bloom, therefore increasing their chance of survival. Continuous spawning over most of the year, together with a major spawning peak in spring combined with the temperaturerelated convergence of hatching and settlement, may give a species a significant reproductive advantage; in the case of the common octopus it is indicative of quite a flexible reproductive strategy, which may be a reason for the wide geographical distribution of this species.

\section{ACKNOWLEDGEMENTS}

Drafts of the manuscript have been considerably improved by comments by Prof. Ángel Guerra and two anonymous reviewers. This research was supported by the Research Committee of the University of Athens.

\section{REFERENCES}

Balguerías, E., C. Hernández-González and C. Perales-Raya 2002. On the identity of Octopus vulgaris Cuvier, 1797 stocks in the Saharan Bank (Northwest Africa) and their spatio-temporal variations in abundance in relation to some environmental factors. Bull. Mar. Sci., 71: 147-163.

Belcari, P., D. Cuccu, M. González, A. Srairi and P. Vidoris. 2002. Distribution and abundance of Octopus vulgaris Cuvier, 1797 (Cephalopoda: Octopoda) in the Mediterranean Sea. Sci. Mar., 66(Suppl. 2): 157-166.

Boletzky, S.v. - 2003. Biology and early life stages in cephalopod molluscs. Adv. Mar. Biol., 44: 144-202.

Caverivière, A., F. Domain and A. Diallo. - 1999. Observations on the influence of temperature on the length of embryonic development in Octopus vulgaris (Senegal). Aquat. Liv. Res., 12: 151-154.

Ellis, R. and D. Gulick. - 1986. Calculus with analytical geometry, $3^{\text {rd }}$ edition. Harcourt Brace Jovanovich Inc., USA.

Giese, A.C. - 1959. Comparative physiology: Annual reproductive cycles of marine invertebrates. Ann. Rev. Physiol., 21: 547-576.

González, A.F., J. Otero, A. Guerra, R. Prego, F.J. Rocha and A.W. Dale. - 2005. Distribution of common octopus and common squid paralarvae in a wind-driven upwelling area (Ria of Vigo, northwestern Spain). J. Plankton Res., 27: 271-277.

Guerra, A. - 1981. Spatial distribution pattern of Octopus vulgaris. J. Zool., 195: 133-146.

Hamel, P., P. Magnan, P. East, M. Lapointe and P. Laurendeau. 1997. Comparison of different models to predict the in situ embryonic developmental rate of fish, with special reference to white sucker (Catostomus commersoni). Can. J. Fish. Aquat. Sci., 54: 190-197.

Hanlon, R.T. - 1977. Laboratory rearing of the Atlantic reef octopus, Octopus briareus Robson, and its potential for mariculture. Proc. World Maric. Soc., 8: 471-482.

Hatanaka, H. - 1979. Studies of the fisheries biology of common octopus off the northwest coast of Africa. Bull. Far Seas Fish. Res. Lab, 17: 13-124.

Hernández-García, V., J.L. Hernández-López and J.J. Castro-Hdez. -2002 . On the reproduction of Octopus vulgaris off the coast of the Canary Islands. Fish. Res., 57: 197-203.

Hochberg, M.E., J. Pickering and W.M. Getz. - 1986. Evaluation of phenology models using field data: case study for the pea aphid, Acyrthosiphon pisum, and the blue alfalfa aphid, Acyrthosiphon kondoi (Homoptera: Aphididae). Environ. Entomol., 15: 227-231.

Hutchinson, G.E. - 1951. Copepodology for the ornithologist. Ecology, 32: 571-577.

Iglesias, J., J.J. Otero, C. Moxica, L. Fuentes and F.J. Sánchez. 2004. The completed life cycle of the octopus (Octopus vulgaris, Cuvier) under culture conditions: paralarval rearing using Artemia and zoeae, and first data on juvenile growth up to 8 months of age. Aquacult. Int., 12: 481-487.

Imamura, S. - 1990. Larval rearing of octopus (Octopus vulgaris Cuvier). The progress of technological development and some problems remained. Collect. Breed., 52: 339-343.

Itami, K., Y. Izawa, S. Maeda and K. Nakai. - 1963. Notes on the laboratory culture of the octopus larvae. Bull. Jap. Soc. Scient. Fish., 29: 514-520.

Jamieson, C. and C. Burns. - 1988. The effects of temperature and food on copepodite development, growth and reproduction in three species of Boeckella (Copepoda: Calanoida). Hydrobiologia, 164: 235-257. 
Katsanevakis, S. and G. Verriopoulos. - 2004a. Den ecology of Octopus vulgaris, Cuvier 1797, on soft sediment: availability and types of shelter. Sci. Mar., 68: 147-157.

Katsanevakis, S. and G. Verriopoulos. - 2004b. Abundance of Octopus vulgaris on soft sediment. Sci. Mar., 68: 553-560.

Katsanevakis, S. and G. Verriopoulos. - 2006. Seasonal population dynamics of Octopus vulgaris in eastern Mediterranean. ICES J. Mar. Sci., 63: 151-160.

Mangold, K. - 1983. Octopus vulgaris. In: P.R. Boyle (ed.), Cephalopod Life Cycles Volume I: Species Accounts, pp. 335364, Academic Press, New York.

Mangold, K. and S. von Boletzky. - 1973. New data on reproductive biology and growth of Octopus vulgaris. Mar. Biol., 19: 7-12.

Rocha, F., A. Guerra and A.F. González. - 2001. A review of reproductive strategies in cephalopods. Biol. Rev., 76: 291-304.

Sakaguchi, H., T. Hamaro and A. Nakazono. - 1999. Occurence of planktonic juveniles of Octopus vulgaris in eastern Iyo-Nada of the Seto Inland sea, Japan. Bull. Jpn. Soc. Fish. Oceanogr., 63, 181-187.
Silva, L., I. Sobrino and F. Ramos. - 2002. Reproductive biology of the common octopus, Octopus vulgaris Cuvier, 1797 (Cephalopoda: Octopodidae) in the Gulf of Cadiz (SW Spain). Bull. Mar. Sci., 71: 837-850.

Vevers, H.G. - 1961. Observations on the laying and hatching of octopus eggs in the society's aquarium. Proc. Zool. Soc. Lond., 137: $311-315$

Villanueva, R. - 1995. Experimental rearing and growth of planktonic Octopus vulgaris from hatching to settlement. Can. J. Fish. Aquat. Sci., 52: 2639-2650.

Wodinsky, J. - 1972. Breeding season of Octopus vulgaris. Mar. Biol., 16: 59-63.

Received December 20, 2005. Accepted May 8, 2006.

Scient. ed.: A. Guerra.

Published online November 15, 2006 